\title{
Letters
}

Website: www.bmj.com

Email: letters@bmj.com

\section{Cancellation of debt must ensure maximum benefit to vulnerable}

EDITOR-It should be difficult for any doctor to ignore Abbasi's recent article on "third world" debt. ${ }^{1}$ The state of health care available to families in between half and two thirds of the world is unacceptable, and the great differences in quality of health care between rich and poor countries are unethical. ${ }^{2}$ However, the experiences of our aid agency in trying to develop hospital care for children in disadvantaged countries leads us to be cautious about advocating simply a cancellation of debts. We have witnessed that an input of money alone to countries which are poorly governed, and where corruption is a way of life, may fail to reach the most vulnerable and needy within the community.

Our agency's view is that all debt to poor and disadvantaged countries should be cancelled but in a more sustainable way than by releasing states from their repayments. Money earmarked for debt repayment should be retrieved but ploughed back fully and immediately into the country's healthcare and education systems. We suggest that this is implemented through the appointment in each repaying country of carefully chosen advocates for women and children. Ideally, partners appointed from within the

\footnotetext{
Advice to authors

We prefer to receive all responses electronically, sent either directly to our website or to the editorial office as email or on a disk. Processing your letter will be delayed unless it arrives in an electronic form.

We are now posting all direct submissions to our website within 24 hours of receipt and our intention is to post all other electronic submissions there as well. All responses will be eligible for publication in the paper journal.

Responses should be under 400 words and relate to articles published in the preceding month. They should include $\leqslant 5$ references, in the Vancouver style, including one to the BMJ article to which they relate. We welcome illustrations.

Please supply each author's current appointment and full address, and a phone or fax number or email address for the corresponding author. We ask authors to declare any competing interest. Please send a stamped addressed envelope if you would like to know whether your letter has been accepted or rejected.

Letters will be edited and may be shortened.

www.bmj.com

letters@bmj.com
}

United Nations should support these local delegates. A committee formed between the UN partners and delegates from the country repaying the debt should thereby ensure that all the money that has been repaid to rich countries is used for health care and education.

Such a system would be more difficult to organise than simple cancellation of debt Care would have to be taken to ensure that existing levels of finance for health care and education are maintained in addition to money resulting from debt repayment. The repayment of debts by the "third world" to rich countries who have prospered from earlier exploitation clearly represents an evil. However, our response to this should be "street wise" and should ensure that the abolition of debt results in maximum benefit to the most vulnerable members of disadvantaged countries.

\section{David Southall honorary director, Child Advocacy} International

Academic Department of Paediatrics, North Staffs Hospital (City General), Stoke on Trent, Staffordshire ST 4 6QG

cai_uk@compuserve.com

1 Abbasi K. Free the slaves. BMJ 1999;318:1568-9. (12 June.) 2 Sogan D, Bridel J, Arzomund M, Shepherd C, Southall D. 21st century health care for children in Afghanistan Pediatrics 1998;102:1193-8.

\section{Developing countries cannot afford high fees for speakers}

EDITOR-Doctors visit Thailand to give lectures at the invitation of Thai universities or royal colleges or are invited by drug firms. Some pay all of their own expenses, or only claim minimal expenses, and give generously of their time. These doctors contribute much to the educational programme in Thailand and to good international relations. However, for the reasons illustrated by the following examples, our Thai colleagues have expressed concern about some of those lecturers who are invited by Thai divisions of international drug firms.

After lecturing in Bangkok one doctor submitted a claim to a local division for two first class air tickets (one of which was for his wife) costing a total of $£ 6000 \quad(\$ 9600)$. Another speaker asked for an honorarium of $£ 2000$ for his one hour talk, refused to be paid by cheque, and asked for a cash payment.
There is no reason why a lecturer should not charge high fees to a rich parent drug company or claim expenses commensurate with those paid to other professionals, but the situation in Thailand, and probably in other developing countries, is different from that in the West. Visiting speakers may not understand that their expenses are not reimbursed by a parent company in the West but come out of the local division's budget. High fees have thus had important repercussions during Thailand's recent economic recession. Also, visitors may not understand that the nature of the social hierarchy in Thailand is such that people of lower seniority would not ask before a visit what the fees and expenses of a visitor are likely to be, nor can they question large fees or expenses, even when they seem excessive.

The payment of high charges for speaking fees uses funds that would otherwise be spent on education and training. The $£ 1000$ spent on a visiting speaker, for instance, could cover the costs of sponsoring a resident for a three year training programme or could cover the total cost of a Thai royal college's annual meetings.

We suspect that these problems are not confined to Thailand, British lecturers, or any particular specialty, but we hope that by understanding the implications of high charges, speakers will be more considerate in making their claims. In the meantime, it is possible that colleagues in some poorer countries will no longer invite lecturers who ask for large fees and expenses. We recommend that, however embarrassing it may be for them, these colleagues make it clear before the visit that only reasonable, affordable expenses may be claimed.

Teerakiat Jargensettasin vice dean Guy Edwards visiting professor Faculty of Medicine, Khon Kaen University, Khon Kaen 40002, Thailand

Competing interests: None declared.

\section{Antidepressants for old people}

GPs should become familiar with one or two antidepressants from each class

EDITOR-Livingston and Livingston cast a sceptical eye over the newer antidepressants in relation to the treatment needs of older people with depression. ${ }^{1}$ Their editorial contained omissions and inaccuracies. They state that subjects aged over 64 with physical disease were excluded from "all the trials cited" in the editorial yet quote research (their reference 5) that addressed precisely this group. 
Likewise, they claim that fluoxetine is the "only newer antidepressant that has been evaluated clinically in depressed patients with organic brain disease" but cite two papers, one concerning citalopram and the other moclobemide, that have evaluated depression in old people with dementia. They overlook important sources of information-for example, the comprehensive report of the National Institutes of Health in 1991, recently updated ${ }^{2}-$ and they lump together all older people, when clearly there are important differences between a fit 65 year old and a frail 85 year old.

The debate they are trying to promote is a tired one. Older people are prone to side effects and have contraindications to a large number of drugs (including some older tricyclic antidepressants), so it makes sense to have a choice; that is precisely what the newer antidepressants offer to older patients. Having a choice improves outcome. In one study of older people, sequential antidepressant regimens that used different classes of antidepressants resulted in a recovery rate of over $80 \% .^{3}$ The newer antidepressants are here to stay. The important questions are not whether they should be used at all but their place alongside psychological approaches in cases resistant to treatment with a first line antidepressant and in the prevention of recurrence.

A more helpful message would be to encourage practitioners who treat older patients to become familiar with one or two antidepressants from each class, as recommended by the Royal Colleges of Psychiatrists and General Practitioners. ${ }^{4}$ It is unnecessary to pit one class of antidepressants against another: there is room for both.

R C Baldwin consultant old age psychiatrist Manchester Royal Infirmary, Manchester M13 9BX rbaldwin@fs1.cmht.nwest.nhs.uk

Competing interests: None declared.

1 Livingston MG, Livingston HM. New antidepressants for old people? BMJ 1999;318:1640-1. (19 June.)

2 Lebowitz BD, Pearson JL, Schneider LS, Reynolds CF 3rd, Alexopoulos GS, Bruce ML, et al. Diagnosis and treatment of depression in late life: consensus statement JAMA 1997;278:1186-90.

3 Flint AJ, Rifat SL The effect of sequential antidepressant treatment on geriatric depression. J Affect Disord 1996:36:95-105.

4 Katona C, Freeling P. Hinchcliffe K, Blanchard M, Wright 4 Katona C, Freeling P, Hinchcliffe K, Blanchard M, Wrigh
A. Recognition and management of depression in late life in general practice: consensus statement. Primary Care in general practice: con

\section{Elderly people are particularly prone to} develop side effects

EDITOR-By discussing mainly data from clinical trials Livingston and Livingston understate the advantages of the newer antidepressants in elderly people. ${ }^{1}$ They cite Song et al's meta-analysis of randomised controlled trials which found no significant difference in total dropout rates between tricyclic antidepressants and selective serotonin reuptake inhibitors.

A more recent meta-analysis found a small but significant difference in total dropout rates in favour of selective serotonin reuptake inhibitors. ${ }^{2}$ An observational study in primary care showed a larger difference: the ratio of the total number who stopped taking antidepressants to the number who started them was $22 \%$ for selective serotonin reuptake inhibitors and 33\% for tricyclic antidepressants. ${ }^{3}$ This suggests that in clinical practice selective serotonin reuptake inhibitors offer a considerable advantage in terms of tolerability, an advantage that is minimised in the highly standardised environment of clinical trials.

Although antidepressants have similar efficacy in trials, this will occur in clinical practice only if patients take a therapeutic dose. Studies in primary care consistently show that patients are more likely to be prescribed a recommended therapeutic dose of a selective serotonin reuptake inhibitor than of a tricyclic antidepressant. This difference remains when allowance is made for the fact that elderly people often respond to doses of tricyclic antidepressants below those recommended in younger adults.

The authors highlight the greater toxicity of tricyclic antidepressants in overdose. Another aspect of safety that deserves consideration is side effects. Elderly people are particularly prone to develop these because of concurrent illness, drug interactions, and the changes of normal ageing. Compared with newer agents the tricyclic antidepressants have more potential to cause serious side effects due to their non-selective action; $\alpha_{1}$ blockade can cause postural hypotension, leading to falls and fractures; muscarinic blockade can cause urinary retention, impaired cognitive functioning, and delirium; the membrane stabilising effect can cause cardiac arrhythmias. A record linkage study showed a significantly increased risk of admission with acute urinary retention among patients prescribed tricyclic antidepressants compared with those prescribed selective serotonin reuptake inhibitors. ${ }^{4}$ The number of contraindications to and cautions against use is greater for tricyclic antidepressants than for selective serotonin reuptake inhibitors.

A recent review concluded that newer antidepressants were preferred in elderly people, although previous response to antidepressants may modify this recommendation. ${ }^{5}$ Data are strongest for the selective serotonin reuptake inhibitors. Tricyclic antidepressants are useful second line agents, but those with high antimuscarinic activity are best avoided. Irrespective of the antidepressant chosen, it is important when treating elderly patients to start with a low dose, increase it gradually, and monitor for side effects.

Peter Haddad consultant psychiatrist Moorside Unit, Trafford General Hospital, Manchester M41 5SL

Competing interests: $\mathrm{Dr}$ Haddad has received lecture fees and conference expenses from the manufacturers of several antidepressants, including selective serotonin reuptake inhibitors. 1 Livingston MG, Livingston HM. New antidepressants for
old people? BMJ 1999;318:1640-1. (19 June.)
2 Anderson IM, Tomenson BM. Treatment discontinuation
with selective serotonin reuptake inhibitors compared
with tricyclic antidepressants: a meta-analysis. BMJ
1995:310:1433-8.
3 Martin RM, Hilton SR, Kerry SM, Richards NM. General practitioners' perceptions of the tolerability of antidepressant drugs: a comparison of selective serotonin reuptak inhibitors and tricyclic antidepressants. BMJ 1997;314:646-51

4 MacDonald TM, McMahon AD, Reid IC, Fenton GW, McDevitt DG. Antidepressant drug use in primary care: a record linkage study in Tayside, Scotland. BMJ 1996;313:860-1.

5 Spigset O, Martensson B. Clinical review: Drug treatment of depression. BMJ 1999;318:1188-91. (1 May.)

\section{Lack of evidence of efficacy is not evidence of lack of efficacy}

EDITOR-Livingston and Livingston's editorial regarding the selection of antidepressants for elderly people rightly points out the dearth of reliable evidence on the comparative efficacy and tolerability of various classes of antidepressants in this age group. ${ }^{1}$ The authors conclude that it is hard to recommend newer drugs on safety grounds other than to those at risk of overdosing. They base this conclusion on a lack of evidence of better tolerability of newer compared with older antidepressants.

The authors cite a meta-analysis that compared dropout rates with tricyclic antidepressants and selective serotonin reuptake inhibitors in clinical trials, which suggested no significant difference between these classes of drugs. ${ }^{2}$ Extrapolating dropout rates in clinical trials to either tolerability or compliance in clinical practice is, however, difficult, and a more recent metaanalysis has disputed these findings. ${ }^{3}$

Perhaps of more relevance to clinical practice is an examination of general practitioners' prescribing habits for antidepressants; this showed that the ratio of dropping out of treatment to starting treatment was $50 \%$ higher for tricyclic antidepressants than for selective serotonin reuptake inhibitors. ${ }^{4}$ How much of this difference is due to tolerability problems in elderly people is unknown.

A lack of evidence of efficacy is not the same as evidence of a lack of efficacy. This is also the case with regard to tolerability. Practice based randomised clinical trials are the gold standard. In the absence of a sound evidence base, however, it is surely best to act on what evidence we have, coupled with our clinical acumen. Clinical observations suggest that patients of all ages generally tolerate selective serotonin reuptake inhibitors better than tricyclic antidepressants. Are we to ignore these observations and deny elderly people drugs that are almost certainly easier for them to take while we wait for definitive studies to be conducted? If so then Livingston and Livingston's power calculations suggest that we may have a very long wait.

R H McAllister-Williams MRC clinical scientist Department of Psychiatry, University of Newcastle upon Tyne, Royal Victoria Infirmary, Newcastle upon Tyne NE1 4LP r.h.mcallister-williams@ncl.ac.uk

Competing interests: Dr McAllister-Williams has received lecture fees, conference expenses, and small sums of money to support research from the manufacturers of several antidepressants, including selective serotonin reuptake inhibitors.

1 Livingston MG, Livingston HM. New antidepressants for old people? BMJ 1999;318:1640-1. (19 June.) 
2 Song F, Freemantle N, Sheldon TA, House A, Watson P, Long A, et al. Selective serotonin reuptake inhibitors: meta-analysis of efficacy and acceptability. BMJ 993;306:683-7.

3 Anderson IM. SSRIs versus tricyclic antidepressants in depressed inpatients: a meta-analysis of efficacy and tolerability. Depression Anxiety 1998;7(suppl 1):11-7.

4 Martin RM, Hilton SR, Kerry SM, Richards NM. General practitioners' perceptions of the tolerability of antidepressant drugs: a comparison of selective serotonin reuptake inhibitors and tricyclic antidepressants. $B M J$ 1997;314:646-51.

\section{Research on antidepressants in the elderly population is scarce}

EDITOR-Livingston and Livingston are right to draw our attention to the paucity of research on antidepressants in the elderly population. ${ }^{1}$ At least five studies comparing tricyclic antidepressants and selective serotonin reuptake inhibitors in elderly people have shown no difference. In all of these comparison studies relatively low doses of tricyclic antidepressants were used, which makes meaningful conclusions difficult to draw, except perhaps that a low dose tricyclic antidepressant may be equivalent to a standard dose serotonin reuptake inhibitor. Another large study of selective serotonin reuptake inhibitors in elderly people showed final mean Hamilton depression scores of 16 (not consistent with full remission ${ }^{2}$ ).

The risks versus the benefits of prescribing newer antidepressants in elderly people depend on the person concerned. Although tricyclic antidepressants should be withheld in people at high risk of suicide, death by overdose of tricyclics is relatively rare and there is some evidence that these drugs may be more efficacious at treating melancholia. ${ }^{3}$

The major difficulty in using tricyclic antidepressants in elderly people is orthostatic hypotension, which can occur at blood concentrations well below therapeutic concentrations. This effect, however, is probably less a function of age than of increasing illness and treatment with multiple drugs. On this evidence, tricyclic antidepressants remain the treatment of choice in elderly patients with uncomplicated depression.

Catherine Gordon specialist registrar in psychiatry Queens Medical Centre, Nottingham NG7 2UH kateg@ndirect.co.uk

Competing interests: None declared.

1 Livingston M, Livingston $\mathrm{H}$. New antidepressants for old people? BMJ 1999;318:1640-1. (19 June.)

2 Tollefson GD, Holman SL. Analysis of the Hamilton depression rating scale factors from a double-bling depression rating scale factors from a double-blind, placebo-controlled trial of fluoxetine in geriatric major depression. Int Clin Psychopharmacol 1993;8:253-9.

3 Roose SP, Glassman AH, Attica E, Woodring S. Comparative efficacy of selective serotonin reuptake inhibitors and tricyclics in the treatment of melancholia. Am J Psychiatry 1994:151:1735-9.

\section{Authors' reply}

EDITOR-In our editorial we were concerned with the primary evidence of efficacy and safety of newer antidepressants in elderly people, and therefore we focused mainly on randomised controlled trials rather than on meta-analyses or reviews even from august bodies such as the National Institutes of Health. Baldwin is correct to point out that we cite trials that support the use of fluoxet- ine in elderly physically ill people who are depressed ${ }^{1}$ and citalopram and moclobemide in depressed people with dementia. ${ }^{2}$

The message of getting to know a few drugs well is sound, but for us the question is which ones. Haddad would exhort us to consider wider sources of information than randomised controlled trials on prescribing in elderly people. We agree, but treatments are available for depression that have already undergone clinical trial in this population. We cite the very few studies of the newer drugs, and surely prescribers (and consumers) would want new alternatives to be submitted similarly to randomised controlled trials.

McAllister-Williams is correct to encourage doctors to do what they can in the clinical context when faced with an elderly person who is depressed, but when we are driven to choose a treatment that has not been subjected to a rigorous randomised controlled trial our treatment is founded on less firm ground. We do not assert that the newer antidepressants are less effective or less well tolerated than tricyclic antidepressants in the over $65 \mathrm{~s}$, simply that claims for efficacy and tolerance have to be justified, as with younger populations.

Gordon would seem to take our position that, in the words of our editorial's subtitle, the evidence of efficacy and tolerability for many new antidepressants in elderly people is thin. We do not see our editorial as promoting a tired debate (Baldwin) about tricyclics versus selective serotonin reuptake inhibitors and other new antidepressant drugs. It is, in our view, a reminder that depressed old people, just like their younger counterparts, are entitled to receive treatment based on evidence and that more studies need to be carried out on antidepressant drug treatments in this important population.

Martin G Livingston consultant psychiatris Hilary M Livingston consultant psychiatrist Southern General Hospital, Glasgow G51 4TF mgl2w@udcf.ac.uk

Competing interests: None declared.

1 Evans M, Hammond M, Wilson K, Lye M, Copeland Placebo controlled treatment trial of depression in elderly physically ill patients. Int J Geriatr Psychiatry 1997;12. $817-24$

2 Nyth AL, Gottfries CG, Lyby K, Smedegaard-Andersen I, Gylding-Sabroe J, Kristensen M, et al. A controlle multicenter trial of citalopram and placebo in elderly multicenter trial of citalopram and placebo in elderly
depressed patients with and without concomitant demendepressed patients with and without co

tia. Acta Psychiatr Scand 1992;86:138-45. 3 Roth M, Mountjoy CQ, Amrein R. Moclobemide in elderly patients with cognitive decline and depression; an international double blind placebo controlled trial. $\mathrm{Br} J$ Psychiatry 1996;168:149-57.

\section{Low molecular weight heparins could be important in cancer}

EDITOR-Kakkar and Williamson clearly state the need for well conducted prospective clinical trials to evaluate the potential role of low molecular weight heparins in improving survival in cancer patients. ${ }^{1}$

In the absence of properly designed trials, indirect data can be extrapolated from trials comparing low molecular weight heparins and unfractionated heparin in the treatment of venous thromboembolism. Reduced mortality in patients with venous thromboembolism who were treated with low molecular weight heparins seemed to be confined to patients with cancer.?

In a meta-analysis of randomised clinical trials (1723 subjects overall: 848 in the low molecular weight heparin group and 875 in the unfractionated heparin group), we evaluated mortality in the first 15 days of treatment, when a true effect of low molecular weight heparins would be expected, and in the three months of subsequent oral anticoagulation. ${ }^{3}$ After a follow up of three months, overall mortality was $3.3 \%$ in the low molecular weight heparin group and $5.9 \%$ in the unfractionated heparin group (relative risk $0.51,95 \%$ confidence interval 0.2 to $0.9, \mathrm{P}<0.01)$. Although there was no significant difference in overall mortality in the first 15 days, the difference during oral anticoagulation was significant $(2.5 \% v 4.5 \%$; $0.48,0.2$ to $0.8, \mathrm{P}<0.03)$. In a separate analysis in patients with a diagnosis of cancer at the time of initial diagnosis of venous thromboembolism, $1.3 \%$ of patients in the low molecular weight heparin group died during the first 15 days of treatment compared with $2.5 \%$ in the unfractionated heparin group $(0.5,0.01$ to $7.7, \mathrm{P}=0.52)$. The difference in mortality in patients with cancer during the 16-90 day follow up period of oral anticoagulation was significant: $12 \%$ in the low molecular weight heparin group and $26 \%$ in the unfractionated heparin group $(0.33,0.1$ to 0.8 , $\mathrm{P}<0.01)$. During the combined period of heparin and oral anticoagulation therapy, mortality was $14 \%$ in patients with cancer treated with low molecular weight heparin and $28 \%$ in those treated with unfractionated heparin $(0.33,0.1$ to $0.8, \mathrm{P}<0.01)$. Mortality in patients without cancer was not significantly different between the groups $(1.9 \%$ ข $2.6 \% ; 0.72,0.3$ to $0.6, \mathrm{P}=0.4)$.

Our observation does not support the hypothesis that the reduction in death in patients with cancer is due to an effect of low molecular weight heparins in preventing thromboembolism. No difference in mortality from all causes was observed in patients without cancer. The cause of reduced mortality in cancer patients treated with low molecular weight heparins is therefore difficult to explain.

Sergio Siragusa haematologist and angiologist Istituto di Ricovero e Cura a Carattere Scientifico, Policlinico S Matteo, Pavia, Italy 27100 s.siragusa@smatteo.pv.it

1 Kakkar AK, Williamson RCN. Antithrombotic therapy in cancer. BMJ 1999:318:1571-2. (12 June)

2 Green D, Hull RD, Brant R, Pineo GF. Lower mortality in cancer patients treated with low-molecular weight heparin versus standard heparin. Lancet 1992;339:1476.

3 Siragusa S, Cosmi B, Piovella F, Hirsh J, Ginsberg JS. Lowmolecular weight heparins and unfractionated heparin in the treatment of patients with acute venous thromboembolism: results of a meta-analysis. Am J Med 1996:100: 269-77. 


\section{Hypoalbuminaemia and transcapillary pressures have role in nephrotic syndrome}

EDITOR-In their article on understanding oedema Diskin et al have overlooked an important body of work that challenges the traditional pathophysiological explanation for the development of oedema in the nephrotic syndrome secondary to renal disease. ${ }^{1}$ Animal as well as several human studies have shown that sodium retention seems to occur as a primary phenomenon in the nephrotic syndrome as a result of increased sodium reabsorption in the collecting duct. $^{2-4}$ This in turn may be due to resistance to atrial natriuretic peptide. ${ }^{5}$

Hypoalbuminaemia and changes in transcapillary pressures, as well as volume regulating hormones and sodium retention, are mechanisms that do have a role in nephrotic, oedematous patients. Whether sodium retention is the dominant mechanism for the development of oedema remains uncertain. For clinicians it is not the oedema but the assessment of intravascular volume status (using clinical and laboratory data) in children with the nephrotic syndrome that remains an inexact science.

Nadeem E Moghal consultant paediatric nephrologist Department of Paediatric Nephrology, Royal Victoria Infirmary, Newcastle upon Tyne NE1 4LP N.E.Moghal@newcastle.ac.uk

Competing interest: None declared.

1 Diskin CJ, Stokes TJ, Dansby LM, Carter TB, Radcliff L, Thomas SG. Towards an understanding of oedema. $B M$ 1999;318:1610-3. (12 June.)

2 Ichikawa I, Rennke HG, Hoyer JR, Badr KF, Schor N, Troy $\mathrm{JL}$, et al. Role for intrarenal mechanisms in the impaired salt excretion of experimental nephrotic syndrome. J Clin Invest 1983;71:91-103.

3 Geers AB, Koomans HA, Roos JC, Boer P, Mees EJD. Functional relationships in the nephrotic syndrome Kidney Int 1984;26:324-30.

4 Bohlin AB, Berg U. Renal sodium handling in minimal change nephrotic syndrome. Arch Dis Child 1984;59:82530.

5 Perico N, Remuzzi G. Edema of the nephrotic syndrome the role of the atrial peptide system. Am J Kidney Dis 1993;22:355-66.

\section{Mibefradil was not rushed to market in United States}

EDITOR-Landow gave a misleading impression of the discussion about mibefradil at the US Food and Drug Administration's Cardio-Renal Advisory Committee meeting of 28 February 1997 and the subsequent withdrawal of the drug from the market in the United States. ${ }^{1}$

The question most extensively discussed at the meeting was whether mibefradil prolongs the QT interval and is therefore likely to induce malignant ventricular arrhythmia. Mibefradil does induce electrocardiographic changes that look disturbing, but the committee (and later the Food and Drug Administration) was impressed by the fact that similar changes can be induced by verapamil and diltiazem; that mibefradil (unlike quinidine, terfenadine, cisapride, astemizole, and other well known drugs that induce torsades de pointes) does not prolong the action potential in vitro; and that mibefradil (again unlike those drugs mentioned above) does not induce malignant arrhythmias in animal experiments. Notwithstanding the doubts expressed during the discussion, the committee recommended that mibefradil should be approved for marketing.

During the time that mibefradil was marketed, there were no reported cases of ventricular arrhythmia associated with mibefradil in patients who did not have other risk factors and who were not receiving concomitant treatment with proarrhythmic drugs. Here again, mibefradfil differs from most drugs that are recognised to be proarrhythmic.

Mibefradil was ultimately removed from the market because of its ability to derange the metabolism of numerous more essential drugs. This problem was anticipated by one member of the Cardio-Renal Advisory Committee and by at least one regulatory agency (in Sweden), but no similar finding had ever been the basis for not approving or for withdrawing a drug in the United States, and the potential impact of the interaction of these drugs was not adequately appreciated by other members of the committee, the sponsor, the Food and Drug Administration, or (to my knowledge) other regulatory agencies. All concerned regret what happened, but we do not believe that our hindsight is less acute than that of Landow.

Robert R Fenichel deputy division director

Division of Cardio-Renal Drug Products, Food and Drug Administration, HFD-110, 5600 Fishers Lane, Rockville, MD 20857, USA

fenichel@cder.fda.gov 1 Landow L. FDA approves drugs even when experts on its
advisory panels raise safety questions. BMJ 1999;318:944.
(3 April.)

\section{General practitioners' experiences of patients' complaints}

In-house mediation can help in reducing general practitioners' stress

EDITOR-I work as a principal in general practice, with part of my list in Lambeth, and was summoned to a service hearing by Lambeth, Southwark and Lewisham Health Authority before 1996. I was therefore particularly interested in Jain and Ogden's article about general practitioners' experiences of complaints.

Although I appreciate the impartiality shown by the health authority, I would question whether its facilitator function is helpful. In my experience the authority's role largely entailed gathering non-critical information; it failed to analyse the quality of the information collected. My summons to a service hearing seemed to be determined more by the acrimony of the complainant than by the case itself. The health authority seemed unable or unwilling to come to a decision itself about the merits of the allegations, and from an early stage it seemed to concentrate on assimilating both sides of the case with a view to proceeding to a service hearing.

In another case, not related to my practice, the same health authority proceeded with a late complaint against a fundholding practice in which there had been an allegation of clinical mismanagement due to a delayed referral. The general practitioner was accused of putting the financial fundholding interests of the practice above clinical need. The health authority invoked a fundholding complaints procedure, although it had no remit under the NHS regulations to proceed along these lines. Over several months it persistently attempted to facilitate an informal meeting between the parties and refused to accept that there was no procedure or regulation laid down for such cases. Finally, only the threat of legal action by the practice persuaded the authority to drop the case.

Facilitation by the health authority tends to delay proceedings and allow the parties to reach unchallenged conclusions that quickly become entrenched and lead to a service hearing. In-house mediation with an early exchange of views has helped to limit the number of hearings mediated by the health authority and has greatly reduced the accompanying stress to general practitioners brought on by well meaning facilitators.

Peter Thomson general practitioner Greyswood Practice, London SW16 6NT

1 Jain A, Ogden J. General practitioners' experiences of patients' complaints: qualitative study. BMJ 1999:318: 1596-9. (12 June.)

\section{Mentoring should be more widespread}

EDITOR-Jain and Ogden's study of general practitioners' experiences of patients' complaints and Baker's editorial on learning from complaints both mention the need for support for doctors about whom complaints are made. ${ }^{12}$ It seems unfortunate that support is not universally available-a feeling heightened when we read quotes from some doctors who participated in the study, who clearly had not come to any satisfactory resolution after the complaint. Resolution, the word used by the authors for the third phase of response to a complaint, implies a good outcome, but for some general practitioners considerable distress or defensive working patterns persisted.

Neither article mentions what form support might take. Support for general practitioners is developing in various forms around the United Kingdom, mainly as counselling services available in times of difficulty or crisis. But why wait for a crisis? We exhort patients to live health promoting lifestyles and regularly have our cars serviced to lessen the likelihood of malfunction, but we don't extend the philosophy of maintenance and prevention to ourselves.

Mentoring and co-tutoring are ways of providing health promotion for doctors ${ }^{3}$; meeting regularly away from work with a trained colleague, one has the focused and sympathetic attention of a skilled person, with confidentiality, to allow reflection on 
any aspect of work, difficulties experienced and opportunities arising, educational issues, and professional development. This may not only lead to better management of difficulties such as complaints but even help to prevent them.

Doctors who take time to reflect are more aware of what they find difficult, of their thoughts and feelings about interactions with patients; this awareness may lead to improvements in quality of work and healthier responses to upsets. There is interest in mentoring from general practitioners; "regular review of work with a mentor" was thought to be appropriate by a quarter of general practitioners surveyed about their support needs. ${ }^{5}$

Mentoring and co-tutoring may also help doctors to feel valued; being listened to does this to people, as we know from patients. Baker says that in the new culture, of which clinical governance is part, "a high value is placed on practitioners," but he doesn't say how this might be communicated. Mentoring supported by employers might be one way.

Doctors who feel valued and have time to reflect and develop probably provide better quality services to patients; mentoring therefore has a contribution to make in the development of clinical governance.

Gail Young general practitioner

Newcastle upon Tyne NE4 9BB

J.A.Spencer@newcastle.ac.uk

1 Jain A, Ogden O. General practitioners' experiences of patients' complaints: qualitative study. BMJ 1999;318: 1596-9. (12 June.)

2 Baker R. Learning from complaints about general practitioners. BMJ 1999;318:1567-8. (12 June.)

3 Freeman R. Towards effective mentoring in general practice. Br J Gen Pract 1997;47:457-60.

Sackin P, Barnett M, Easthaugh A, Paxton P. Peersupported learning. Br J Gen Pract 1997;47:67-8.

5 Young $\mathrm{G}$, Spencer J General practitioners' views about the non for a stress sueport service. Fan 517-21.

\section{Prison officers can recognise hidden psychiatric morbidity in prisoners}

EDIToR-Prisons in England and Wales are known to house a considerable number of mentally ill people. ${ }^{1-3}$ Many of these people probably pass through health screening undetected when they are received into prison and remain on ordinary location (on prison wings) without ever coming to the attention of a doctor. ${ }^{45}$

During two visits to large local male remand prisons as a guest medical inspector with the Inspectorate of Prisons I decided to see how difficult it was to identify hitherto undetected mental illness in prisoners on ordinary prison location. I asked prison officers to identify inmates on their landing whom they considered to be odd, strange, or behaviourally disturbed. The officers had no difficulty identifying between two and five (out of 35-40) inmates per landing on each of the six landings I surveyed. The description of the behaviour of some of these prisoners strongly suggested that they were psychotic.
I approached every prisoner identified to me who was available (15 in total) and interviewed each in turn in private for 10 minutes. I was explicit about the purpose of the interview and the limits of confidentiality; all were willing to speak to me. Two thirds showed clear signs of mental illness, most being floridly psychotic. Subsequent inspection of prison medical records showed that prison healthcare staff were not aware of any important mental health problems in seven cases, two of the prisoners were thought to have schizophrenia in remission, and one of the prisoners was deemed to have a personality disorder. One man posed such a risk to his cellmate by virtue of his delusional beliefs that I breached confidentiality and informed one of the prison medical officers.

This was only a snapshot survey of two prisons. These findings suggest, however, that prison officers can readily identify at least some of the prisoners with severe hidden psychiatric morbidity. If individuals identified as having such morbidity underwent a more formal screen for mental health problems a considerable number of mentally ill prisoners might get access to the treatment they need.

Luke Birmingham lecturer in forensic psychiatry University of Birmingham, Reaside Clinic, Birmingham B45 9BE

1 Singleton N, Meltzer H, Gatward R, Coid J Deasy D. Psychiatric morbidity among prisoners in England and Wales. atric morbidity among prisoner

2 Brooke D, Tavlor C, Gunn J, Maden A. Point prevalence of mental disorder in unconvicted male prisoners in England .

3 Gunn J, Maden A, Swinton M. Mentally disordered prisomers. Gunn J, Maden A, Swinton

D. Prevalence of mentas

4 Birmingham L, Mason D, Grubin D. Prevalence of mental disorder in remand prisoners: consecutive case study. $B M J$ 1996;313:1521-4.

5 Birmingham L, Mason D, Grubin D. A follow-up study of mentally disordered men remanded to prison. Criminal Behaviour and Mental Health 1998;8:202-13.

\section{Reducing risk of recurrent coronary heart disease in Cornwall}

EdiTor-Bradley and Cupples end their editorial on reducing recurrent coronary heart disease by asking whether anyone has a better idea of how to improve performance in this area ${ }^{1}$ Earlier they say that adequate resources would be needed to ensure a systematic approach to the secondary prevention of coronary heart disease in primary care and that primary care groups would be well placed to implement this. Such a scheme has begun in the Carrick Primary Care Group in Cornwall.

For the next two years the British Heart Foundation will fund two liaison nurses to ease the discharge of coronary patients from the Royal Cornwall Hospital into the community, as well as the training of a lead nurse from each practice. The primary care group will give extra monies to each of their 13 practices for a scheme that includes creating a register of patients with coronary heart disease, starting a call and recall system, and developing improved links with acute care-that is, structured long term care.

Campbell et al showed that nurse run secondary prevention clinics in primary care can reduce risk factors for the recurrence of coronary events. ${ }^{2}$ The widespread adoption of such clinics will need the same amount of funding as that currently provided for the management of asthma and diabetes.

Carrick Primary Care Group are to be congratulated for doing what the government should have done when it initiated payment for some management of chronic diseases in general practice. All primary care groups should be persuaded to follow this example, if necessary using innovative methods of joint funding.

H M Dalal general practitioner

Truro TR1 2LZ

dalalha@cht.swest.nhs.uk

Hugh Bethell chairman

Secondary Prevention and Rehabilitation

Committee, Coronary Prevention Group, London WC1H 0BT

1 Bradley F, Cupples ME. Reducing the risk of recurrent coronary heart disease. BMJ 1999:318:1499-500. (5 June) 2 Campbell NC, Thain J, Deans HG, Ritchie LD, Rawles JM, Squair J. Secondary prevention clinics for coronary heart Squair J. Secondary prevention clinics for coronary heart
disease: randomised trial of effect on health. BMJ disease: random

\section{Is recruitment more difficult with a placebo arm in RCTs?}

\section{Methodological issues will have affected results}

EDitor-Welton et al found that the proportion of women who were willing to participate in a randomised controlled trial of hormone replacement therapy was higher if participation in a trial without a placebo arm was offered rather than participation in one with a placebo arm, although the difference was of borderline significance. ${ }^{1}$ Their conclusion was that inclusion of a placebo arm may reduce patients' willingness to participate in a trial. We do not believe that this conclusion is justified.

Allocation of participants to either of the comparison groups was by the woman's choice of appointment time: the nurses offered participation in trials with and without placebo groups in alternate weeks. This is not random allocation, in which only chance can influence which group a participant is allocated to. ${ }^{2}$ In this study the nurses could predict in which weeks they would be offering participation in trials with or without placebo groups and so could have influenced the choice of appointment time. This kind of bias would have been avoided by randomising the weekly blocks, the intervention for that week being revealed to the nurses only after all appointments for that week were made.

The nurses' explanation of the reason for using a placebo could have influenced willingness to participate. We would have been reassured that nurses' explanations were consistent and neutral by knowing that rates of willingness to participate across 
practices were similar. A lower rate of willingness to participate in some practices would imply differences between nurses in the way they described the reasons for inclusion of a placebo-that is, that it is not the placebo itself but the way in which it is explained that influences the decision to participate. This would make the study's conclusion invalid.

The study shows only that the use of placebos may influence rates of willingness to participate, not actual participation rates, in a trial of hormone replacement therapy. We are concerned that this paper may be used to justify not including a placebo in randomised controlled trials. It is important to include a placebo when the only treatments available are of unknown efficacy or safety. ${ }^{3}$ The real challenge is to develop ways of effectively explaining the reasons for using a placebo to potential participants when a placebo is ethically justified.

Lindsay Forbes lecturer in public health medicine Sue Chinn reader in medical statistics

Jose Figueroa-Munoz lecturer in public health

medicine

Paul Seed lecturer in medical statistics

Department of Public Health Sciences, Guy's, King's and St Thomas's School of Medicine, London SE1 3QD

lindsay.forbes@kcl.ac.uk

1 Welton AJ, Vickers MR, Cooper JA, Meade TW, Marteau TM. Is recruitment more difficult with a placebo arm in randomised controlled trials? A quasirandomised, interview based study. BMJ 1999;318:1114-7. (24 April.)

2 Altman DG, Bland JM. Treatment allocation in controlled trial: why randomise? BMJ 1999;318:1209. (1 May.)

3 Pocock SJ. Clinical trials: a practical approach. New York: John Wiley, 1983.

\section{Authors' reply}

EDITOR-Our conclusion that including a placebo arm may reduce willingness to take part in a trial was tentative and qualified. We drew explicit attention to the difference between expressed willingness and actual participation. So on these two points Forbes et al have simply repeated what we ourselves said.

Random allocation as suggested by Forbes et al would have been ideal but was not practicable. Appointments were arranged and rearranged entirely according to patients' preferences and their own timetables and often less than a week in advance. To have insisted that all appointments were made for each week before we allocated the trial group would have reduced flexibility to make and reschedule appointments, thus increasing the length and costs of the study. There was no evidence to suggest that the method we used resulted in the biased selection of women to weeks during which one or other of the trials was being explained.

Nurses were centrally trained beforehand, and their explanations of the two trials were according to standardised scripts and monitored by the use of tape recordings of a patient's visit with each nurse. Any differences between practices in expressed willingness to take part in either trial will almost certainly have been due to a variety of influences, such as the local awareness of issues to do with hormone replacement therapy and the prevalence of its use.
There is nothing in our paper to justify not including a placebo when it is scientifically necessary to do so. Rather, we hope that our results will help researchers to set realistic recruitment targets. We also drew attention to the importance to participants of trial information indicating the potential benefits for others besides themselves.

A J Welton health psychologist

M R Vickers senior scientist

J A Cooper statistician

T W Meade professor

Medical Research Council Epidemiology and Medical Care Unit, Wolfson Institute of Preventive Medicine, St Bartholomew's and Royal London Hospital School of Medicine and Dentistry, London ECIM 6BQ

T M Marteau professor

Psychology and Genetics Research Group, King's College London, Guy's Campus, London SE1 9RT

\section{Differences in death rates in English hospitals}

\section{Effects of admission rates may have been understated}

EDITOR-Unlike Jarman et al, I do not yet think that we can state with confidence that "more doctors means fewer deaths." As the authors make clear, there has been a lively discussion on comparative hospital death rates in the United States. From this debate two points emerge clearly: for any given population the standardised admissions rate is positively correlated with the standardised death rate but is inversely correlated with the standardised hospital death rate (defined as any death within 30 days of a hospital admission). ${ }^{23}$ Where a population is admitted to hospital fairly frequently a higher proportion of admissions will not be associated with subsequent death; hence there will be a lower apparent hospital mortality. A study in Ohio found African-Americans to have consistently higher admissions and lower severityadjusted hospital mortality than white patients treated at the same hospitals. ${ }^{4}$

It was therefore informative that the authors included with their explanatory variables a calculation of the standardised admission ratio (though not separated into "all cases" and "emergencies" for the two versions of their model). Unfortunately, the figures used were the aggregates for the health authority of hospital location rather than individual figures for each hospital's emergency catchment area (often very different). Even in this form, standardised admissions entered significantly into both the all cases and the emergency multiple regression models. It is not impossible that a fully specified version of this variable might displace some of the doctor variables; the observed relation could simply be "More doctors means more admissions."

One way to resolve this issue would be to exploit a generally observed feature of the NHS in England-that there is relatively little overlap of acute hospitals' geographical catchment areas for adult emergency admissions. Hence it should be possible to repeat the authors' analysis exactly but with data aggregated by electoral ward of residence rather than by hospital of admission. The aggregate discharge data would be the same (except that true standardised admission rates could be used). The community data could then be used directly (with numbers of general practitioners per head calculated from family health services registers), but the hospital data would need to be cross attributed. It would also then be possible to match hospital mortality data with community data on general mortality and life expectancy.

Tom Hennell strategic analyst

NHS Executive North West, Warrington WA3 7QN thennell@doh.gov.uk

1 Jarman B, Gault S, Alves B, Hider A, Dolan S, Cook A, et al Explaining differences in English hospital death rates using routinely collected data. $B M J$ 1999;318:1515-20. (5 June.)

2 Welch WP, Miller ME, Welch HG, Fisher ES, Wennberg JE Geographic variation in expenditures for physicians' services in the United States. N Engl J Med 1993;328:621-7.

Heall Care Financ An.

3 Health Care Financing Administration. Hospitalization and mortality data for states. Washington, DC: Department of Healh and Human Services, 1992. (Medicare hospital information report; 1992 technical supplement, section D.) 4 Manheim LM, Feinglass J, Shortell SM, Hughes EFX. Regional variation in Medicare hospital mortality. Inquiry 1992;29:55-66

\section{Data are inadequate basis for drawing conclusion of paper}

EDITOR-Efforts to compare the quality of care among hospitals have defeated many investigators in the past. In the latest attempt Jarman et al try to explain differences in English hospital death rates using routinely collected data. ${ }^{1}$ Their main finding is an inverse association between hospital death rates and the number of hospital doctors and general practitioners, from which they conclude that ratios of doctors to population "seem to be critical determinants of standardised hospital death rates; the higher these ratios, the lower the death rates." By implication, and as widely interpreted by the press, hospitals with fewer doctors have, as a result, higher death rates. This may be true, but the data are an inadequate basis for drawing that conclusion.

The strength or weakness of such investigations hinges on the accuracy of the measurement of prognostic or risk factors in patients treated by the hospitals being compared. In this study the severity of the primary illness could not be estimated and comorbidity was limited to a count of subdiagnoses for each patient in hospital episode statistics. The inadequacy of such routine data has been well documented by the NHS Executive, ${ }^{2}$ Iezzoni et al $^{3}$ (Iezzoni being one of the authors), and Jencks et al. ${ }^{4}$ In addition, comorbidity, when measured carefully, has an impact on mortality. ${ }^{5}$ The dangers of using inadequate information has been shown by Iezonni et al, who reported the counterintuitive finding that many subdiagnoses-for example, adult onset diabetes mellitus, essential hypertension, previous myocardial infarction, angina, and ventricular premature beatswere associated with lower death rates. ${ }^{3}$ Much the same finding had previously been reported by Jencks et al. ${ }^{4}$ 
Severity of illness and comorbidity are best judged prospectively, preferably in "consultation with physicians." Second best is retrospective review of individual patients' records comparing condition specific diagnoses and procedures case by case. The least satisfactory approach is to rely on routinely collected undifferentiated data, as in the study of Jarman et al. The authors are aware of possible shortcomings of their approach, writing that "a matched pair study of patients admitted to hospitals with high and low standardised mortality ratios could help to elucidate [their] findings." Without such an investigation, the public, as well as the profession, is left to draw conclusions that may be incorrect.

John P Bunker visiting professor

Department of Epidemiology and Public Health, University College London School of Medicine, London WC1

Nick Black professor

Department of Public Health and Policy, London School of Hygiene and Tropical Medicine, London WC1E 7HT

1 Jarman B, Gault S, Alves B, Hider A, Dolan S, Cook A, et al. Explaining differences in English hospital death rate using routinely collected data. BMJ 1999;318:1515-20. (5 une.)

2 NHS Executive. Quality and performance in the NHS: clinical indicators. Leeds: NHSE, 1999.

3 Iezonni LI, Foley SM, Daley J, Hughes J, Fisher ES, Heeren T. Comorbidities, complications, and coding bias: does the number of diagnosis codes matter in predicting in-hospital mortality? JAMA 1992;267:2197-203.

4 Jencks SF, Williams DK, Kay TL. Assessing hospitalassociated deaths from discharge data: the role of length of stay and comorbidities. JAMA 1988;260:2240-6.

5 Imamura K, Black N. Does comorbidity affect the outcome f surn J Qual Health Care 1998;10:113-23.

\section{Competing interests are relevant to lectures approved for PGEA}

EDITOR-In journals authors are expected to declare any competing interests. In the context of lectures or workshops that are approved for postgraduate education allowance, however, when a group of general practitioners gather specifically to learn, there is no such onus on the lecturer. Thus a talk to 30 primary care prescribers can be delivered by a person who has a direct stake in a particular treatment. Would it not be sensible to ask all providers of talks approved for postgraduate education allowance or continuing medical education to offer this information at the time they give their talks?

If I was aware that a lecture on impotence was being given by a urologist whose department was funded by Rhino Horn International my own interpretation of his recommendations would take that into account. Of course this would never happen-our ethical standards are too high for a colleague's impartiality to be questioned. If it is important enough for journals to take a stand on competing interests, however, then why not clinicians generally? It would perhaps be appropriate for those who have undeclared competing interests to be fined-in postgraduate education allowance/continuing medical education units for the professional transgressors.
Pawan Randev general practitioner Measham Medical Unit, Measham, Near Swadlincote, Derbyshire DE12 7HR randev@globalnet.co.uk

Competing interests: None declared.

\section{Policy must separate need for hospital beds from demand}

EDITOR-Whether or not the private finance initiative has any real advantages (and I have yet to meet a defender of it) is one question; the appropriate number of hospital beds is another. ${ }^{1}$ There is of course no right number of hospital beds: if beds are there they will tend to be filled.

Bed occupancy rates are relatively consistent (at about 80\%) throughout western Europe, although the numbers of hospital beds per capita vary fourfold. If anything, countries with fewer beds tend to have lower occupancy rates. It is almost impossible to separate need for hospital beds from demand. Icelanders are almost certainly not four times more likely to become ill than Danish or Spanish people, but they do spend almost four times as many days in hospital.

The problem with hospital beds is that as long as they are there they tend to inhibit the development of alternatives to admission to hospital. The real policy decision is therefore whether we should devote more health services resources to hospital care or more resources to care outside hospitals.

Pollock has nailed her colours to the mast as a defender of hospitals; this implies that she believes fewer resources should be devoted to care outside hospitals. My own instinct is towards demedicalisation, but currently there is little to say which approach has more merits.

Tom Marshall honorary lecturer in public health medicine

University of Birmingham, Birmingham B15 2TT marshatp@hsrcl.bham.ac.uk

1 Pollock AM, Dunnigan MG, Gaffney D, Price D, Shaoul J. The private finance initiative: Planning the "new" NHS: The private for the ilst ce: Planning the "19, NHS: (17 July.)

\section{New epidemiological research in Europe may be thwarted by short term funding}

EDITOR-The European Union's fifth framework programme of research is making available in 1999 some 850 million euros for projects in biomedicine, with the main objective of prompting new research on key themes for the health of European citizens. Whether this objective is achieved will depend critically on the length of funding.

The standard maximum time for a contract issued by the European Commission is still three years. Clearly, this is totally unrealistic for most research in epidemiology, as it is for research in environmental and occupational health and in evaluating treatments or health services through randomised trials. In our extensive experience as principal investigators, any research that entails the participation of many centres (as in any European study by definition) and the collection of information on human subjects, whether by questionnaires, direct examination (treated or observed), or consultation of already existing records, usually demands a minimum of five years. This includes a minimum of one year to activate an already formed international group of investigators, two to three years to collect data, and two years to check, edit, and analyse data.

What will be the consequences of granting three year contracts?

Firstly, funds may fall short of achieving the aim of starting new research rather than just supporting the ongoing programme. Secondly, projects will produce only preliminary results, often not publishable other than in abstract form. Thirdly, time consuming quality control procedures essential to ensure comparability of results between and within countries may be sacrificed to the time constraint. Fourthly, centres with less experience, which would benefit from participation in multinational studies with leading centres, will tend not to be included because they usually slow down the pace of research. Finally, requests to extend the contract will occur at the last minute, generating administrative overload to gain extensions that will still be inadequate for the time that the research needs.

To overcome this serious shortcoming we offer a simple proposal. In the negotiation phase (starting soon) between the European Commission and the investigators of the projects that have successfully gone through the peer review process, a given amount of the funds assigned to an epidemiological project should be spread (if required and well argued for by the principal investigator) over five years rather than be concentrated in an illusory three years. Should the administrative management for the European Commission be more onerous over five years than over three, a small percentage of the assigned sum could be retained for the purpose- - this will always be much less costly than the destructive wastage of resources caused by highly incongruous time schedules.

Rodolfo Saracci director of research in epidemiology International Epidemiological Association, National Research Council, 56100 Pisa, Italy

Josep Anto' head of respiratory and environmental health research unit

Institut Municipal d'Investigacio' Medica, 08003 Barcelona, Spain

Jorn Olsen professor of epidemiology Danish Epidemiological Science Centre, 8000 Aarhus C, Denmark

Anthony McMichael professor of epidemiology London School of Hygiene and Tropical Medicine, London WC1E 7HT

Dimitrios Trichopoulos professor of epidemiology Harvard University and University of Athens, Boston, MA 02115, USA

\section{Rapid responses} $e \mathrm{BM}$

Correspondence submitted electronically is available on our website www.bmj.com 